\title{
Determining Temporal Aggregation And Seasonality Problems In Malaysia Housing Index
}

\author{
Chin Tiong Cheng, Janice Lee*, Hishamuddin Mohd Ali
}

Faculty of Geoinformation and Real Estate, Universiti Teknologi Malaysia, 81310 UTM Johor Bahru, Malaysia

*Corresponding author: janicelee@utm.my

\begin{abstract}
Nowadays, housing index not merely act as housing performance indicator but also been transformed into financial product that based on housing index. There are two issues to be considered in this paper which are temporal aggregation and seasonality problem in housing index. Seasonality appeared in time series when the price or index movement is repetitive around the trend line. If the housing index consists of seasonal effect it will mislead measurement on real housing performance based on economic situation. In other words, cyclical effect should be avoided in measuring housing performance. Temporal aggregation in constructing house price index may lead to missing information for certain periods and variability in house price is smooth. As a result, the evaluation on housing performance becomes unrealistic. In order to investigate these problems quality adjusted index will be developed by hedonic model based on Laspeyres, Paasche, Fisher and time dummy price index formula. The case study to be investigated is housing index of double storey houses in Plentong Johor. This study found that house price index that developed from different level of temporal aggregation will lead to different risk and return and seasonality effect is exist in house price index Plentong.
\end{abstract}

Keywords: Temporal aggregation, seasonal analysis, seasonal adjustment, housing index

(C) 2016 Penerbit UTM Press. All rights reserved

\subsection{INTRODUCTION}

The housing market is one of the largest asset bases in Malaysia. The performance of housing market is important to several parties such as the government, financial institutions, homeowners and investors. This is because downtrend or uptrend of housing performance will directly affect decision making by these parties such as government housing policy. Therefore, a housing index is an important indicator to measure housing performance in specific locality. Moreover, rapid growth of property as investment vehicle leads to development of financial products such as housing derivative or home equity insurance. In order to ensure the reliability of housing derivatives index or other financial products related to housing index. It is important to determine the presence of two issues when developing a housing index which are (i) temporal aggregation and (ii) seasonality problems. Therefore, this study will investigate these two issues in hampering the housing index.

Temporal aggregation happened when different periods of data are aggregated to construct price index [8]. For an example, the daily data are aggregated to develop quarterly index. Existing housing indices that are published in quarterly form such as Malaysian Housing Price Index, IPD property index and NPI NCREIF property index are exposed to the problem of temporal aggregation as compared to monthly indices. The problem of quarterly index is the restriction of monthly coefficients to be equal within each quarter. For example the monthly coefficient of January, February and March remain constants then move to April. This assumption is questionable since the supply and demand of housing markets is changing over time [21]. In addition, temporal aggregation will lead to smoother and erroneously eliminate noise in house price movements [8]. Therefore, it may induce bias in risk and return of real estate and housing index. As a result, house prices become artificially less risky and the volatility of house price is understated.

Temporal aggregation can affect the specification models, estimation of parameters and efficiency of forecasting [2,28]. Moreover, previous researcher pointed out that narrower time interval will hamper seasonality analysis of house price such as quarterly index is impossible to determine seasonality effect in monthly form [8]. There are some studies related to the effects of temporal aggregation in housing index. It will smooths price variability across time because spot values are averaged [4]. Two researches identified that although most disaggregated (monthly) housing index should be used but temporal aggregation does not matter because the differences of returns and volatilities are small among different level of temporal aggregation [6,21]. Besides, housing indices can be a basis for issuance of derivative securities so temporal aggregation issues must be investigated before constructing an index [4]. Therefore, it is necessary to identify whether temporal aggregation distort calculating risk and return using Malaysia Housing Index.

Besides of temporal aggregation study it is important to determine the existence of seasonality problem in house price index. Seasonality in a time series as a pattern that tends to repeat from year to year [14] by giving example of monthly sales data for a retailer. In other word, seasonality appears in time series when the price or index movement is repetitive around the trend line and will mislead measurement on housing performance. The phenomenon can due to weak form efficiency in real estate price indices return [23]. Therefore, such repeating 
pattern should be seasonally adjusted in order to obtain real housing performance. The factors such as household moving pattern, marriages and family formation rates contribute to housing seasonality [26]. Seasonality problem in house price exist when buyers or seller purchase or sell homes based on a number of factors common to most households such as school cycles, weather, or holidays [18]. A few studies confirmed the existence of seasonality in house price below. An empirical study of seasonality covering 138 Core Based Statistical Areas across United States and found that on average home prices peak in June and hit the lowest value in January [18]. Another empirical study [13] stated house prices are higher on average in the summer by $0.86 \%$ to $3.75 \%$. Furthermore a study [13] using data from Greek region and it gives a similar result which is property prices are affected by seasonal, spatial structural and economic effects. Some past studies also indicate the existence of seasonality in house price [10,24]. Moreover, price indices with seasonal pattern will be seasonally adjusted before being released to the public [8,24]. Malaysia definitely has different culture and socioeconomic structure compared to other countries. For an example, Malaysia has different festival and public holiday. This will make seasonal pattern of Malaysia house price different from other.

Malaysia residential property contributed RM 303.9 billion or $27.4 \%$ of total banking system loans in Malaysia [17]. In addition, household debt/GDP(\%) is increasing from $63.5 \%$ in year 200 to $82.9 \%$ in year 2013 [5]. Therefore, Malaysia economy and financial institution can be affected by housing performance such as property bubble. Apart from that, the study area is under the development of Iskandar Region in Johor Bahru and a lot of residential developments are emerging in this area. It will provide more opportunities of housing investment to Malaysians and foreigners. So, the housing performance should be well monitored through a reliable housing index.

To conclude, this study will enhance the reliability of Malaysia housing index in monitoring purpose and developing financial product linked to housing index in future

\subsection{INDEX CONSTRUCTION METHODS}

The hedonic method recognises that a property is a composite product that can be described by their attributes or characteristics. The attributes are not sold separately, yet regressing the attributes on the sales price of the composite product yields the marginal contribution of each attribute to the sales price [26]. Previous research [11] claimed that the demand and supply for the properties implicitly determine the characteristics' marginal contributions to the prices of the properties. Regression techniques can be used to estimate those marginal contributions or shadow prices. The main advantage of hedonic regression method is to provide quality adjusted price indices. Hedonic regression methods used to formulate housing indices are hedonic time dummy index, Laspeyres, Passche and Fisher index are using hedonic regression method to. These methods will be adopted in this study to achieve both objectives mentioned above.

\section{a) HEDONIC MODEL}

The property price $P_{n}^{t}$ of property $\mathrm{n}$ in period t is a function of a fixed number of K characteristics measured by "quantities" $\left(Z_{n k}^{t}\right)$ [11]. The $\mathrm{T}+1$ time periods going from the base period 0 to period T. Model 2.1 and 2.2 indicated standard regression techniques which are parametric model used to estimate the marginal contributions of each characteristic

$$
\begin{gathered}
\mathrm{P}_{\mathrm{n}}^{\mathrm{t}}=\beta_{0}^{\mathrm{t}}+\sum_{\mathrm{k}=1}^{\mathrm{k}} \beta_{\mathrm{k}}^{\mathrm{t}} \mathrm{Z}_{\mathrm{nk}}^{\mathrm{t}}+\varepsilon_{\mathrm{n}}^{\mathrm{t}}(2.1) \\
\ln \mathrm{P}_{\mathrm{n}}^{\mathrm{t}}=\beta_{0}^{\mathrm{t}}+\sum_{\mathrm{k}=1}^{\mathrm{k}} \beta_{\mathrm{k}}^{\mathrm{t}} \mathrm{Z}_{\mathrm{nk}}^{\mathrm{t}}+\varepsilon_{\mathrm{n}}^{\mathrm{t}}
\end{gathered}
$$

The characteristic parameters $\beta_{k}^{t}$ in 2.1 and 2.2 are allowed to change over time. It is an idea that housing market conditions determine the marginal contributions of the characteristics. But due to demand and supply condition changes there is no priori reason to expect that these contributions are constant [22]. Thus the Equation 2.3 shown that the hedonic model is transforming into constrain versions and time dependent intercept terms $\left(\beta_{0}^{t}\right)$ at below can be converted into a constant quality price index.

$$
\ln P_{n}^{t}=\beta_{0}^{t}+\sum_{k=1}^{\mathrm{k}} \beta_{\mathrm{k}}^{\mathrm{t}} \mathrm{Z}_{\mathrm{nk}}^{\mathrm{t}}+\varepsilon_{\mathrm{n}}^{\mathrm{t}}
$$

\section{b) HEDONIC TIME DUMMY VARIABLE METHOD}

The time dummy variable approach used to construct quality adjusted price index in academic studies. The model 2.4 for time dummy variable approach is stated as below. Running one overall regression on the pooled data of the samples $\mathrm{S}(0), \mathrm{S}(1)$, ..S(T) relating to periods $\mathrm{t}=0, \ldots, \mathrm{T}$ (with sizes $\mathrm{N}(0), \mathrm{N}(1), \ldots, \mathrm{N}(\mathrm{T}))$ yields coefficients $\beta^{0}, \delta^{t}(\mathrm{t}=1, \ldots \mathrm{T})$ and $\beta_{k}(\mathrm{k}=1, \ldots, \mathrm{K})$. The time dummy parameter shifts the hedonic surface upwards or downwards and measures the effects of "time" on the logarithm of price. Exponentiating the time dummy coefficients thus controls for changes in the quantities of the characteristics and provides a measure of quality-adjusted house price change between the base period 0 and each comparison period t. Therefore, the time dummy index going from period 0 to period t is shown in model 2.5 .

$$
\begin{gathered}
\ln P_{\mathrm{n}}^{\mathrm{t}}=\beta_{0}+\sum_{\mathrm{t}=1}^{\mathrm{T}} \delta^{\mathrm{t}} \mathrm{D}_{\mathrm{n}}^{\mathrm{t}}+\sum_{\mathrm{k}=1}^{\mathrm{k}} \beta_{\mathrm{k}} \mathrm{Z}_{\mathrm{nk}}^{\mathrm{t}}+\varepsilon_{\mathrm{n}}^{\mathrm{t}}(2.4) \\
\mathrm{P}_{\mathrm{TD}}^{0 \mathrm{t}}=\exp \left(\delta^{\mathrm{t}}\right)
\end{gathered}
$$




\section{c) HEDONIC IMPUTATION METHOD}

This method require cross sectional regression. In order to carry out this method it need to yield the implicit price of property attributes of based period $(0)$ and comparison period $(\mathrm{t})$. The $\mathrm{t}$ prices of properties sold in period 0 cannot be observed and are "missing" because it may not be resold in period t and vice versa [11]. In order to apply standard index number formulae these "missing prices" must be imputed. Hedonic imputation indices conduct this by using predicted prices and evaluated at fixed characteristics based on the hedonic regressions for all time periods. It also consists of Laspeyres $\left(P_{H D I L}^{0 t}\right)$, Paasche $\left(P_{H D I P}^{0 t}\right)$ and Fisher $\left(P_{H D I F}^{0 t}\right)$ price index formula by using hedonic imputation method.

$$
\begin{gathered}
\mathrm{P}_{\mathrm{HDIL}}^{0 \mathrm{t}}=\frac{\beta_{0}^{\mathrm{t}}+\sum_{\mathrm{k}=1}^{\mathrm{k}} \beta_{\mathrm{k}}^{\mathrm{t}} \mathrm{z}_{\mathrm{nk}}^{0}}{\beta_{0}^{0}+\sum_{\mathrm{k}=1}^{\mathrm{k}} \beta_{\mathrm{k}}^{0} \mathrm{z}_{\mathrm{nk}}^{0}}(2.6) \\
\mathrm{P}_{\mathrm{HDIP}}^{0 \mathrm{t}}=\frac{\beta_{0}^{\mathrm{t}}+\sum_{\mathrm{k}=1}^{\mathrm{k}} \beta_{\mathrm{k}}^{\mathrm{t}} \mathrm{z}_{\mathrm{nk}}^{\mathrm{t}}}{\beta_{0}^{0}+\sum_{\mathrm{k}=1}^{\mathrm{k}} \beta_{\mathrm{k}}^{0} \mathrm{z}_{\mathrm{nk}}^{\mathrm{t}}}(2.7) \\
\mathrm{P}_{\mathrm{HDIF}}^{0 \mathrm{t}}=\left[\mathrm{P}_{\mathrm{HDIL}}^{0 \mathrm{t}} \mathrm{xP} \mathrm{P}_{\mathrm{HDIP}}^{0 \mathrm{t}}\right]^{\frac{1}{2}}(2.8)
\end{gathered}
$$

\subsection{Temporal Aggregation Analysis}

By following the work of [6], six joint null hypotheses are used to determine temporal aggregation of a model. It needed time dummies to conduct this test. The six null hypotheses are stated as follow:

$$
\begin{aligned}
H_{0}^{m, q} & : \phi_{m 1}=\phi_{m 2}=\phi_{m 3}=\phi^{q 1} ; \phi_{m 4}=\phi_{m 5}=\phi_{m 6}=\phi^{q 2} \\
H_{0}^{m, s} & : \phi_{m 7}=\phi_{m 8}=\phi_{m 9}=\phi^{q 3} ; \phi_{m 10}=\phi_{m 11}=\phi_{m 12}=\phi^{q 4} \\
& : \phi_{m 7}=\phi_{m 8}=\phi_{m 3}=\phi_{m 4}=\phi_{m 5}=\phi_{m 10}=\phi^{s 1} \\
H_{0}^{m, y} & : \phi_{m 1}=\phi_{m 11}=\phi_{m 12}=\phi_{m 3}=\phi_{m 4}=\phi_{m 5}=\phi_{m 6}=\phi_{m 7} \\
& : \phi_{m 8}=\phi_{m 9}=\phi_{m 10}=\phi_{m 11}=\phi_{m 12}=\phi^{y 1} \\
H_{0}^{q, s} & : \phi_{q 1}=\phi_{q 2}=\phi^{s 1}=\phi_{q 3}=\phi_{q 4}=\phi^{s 2} \\
H_{0}^{q, y} & : \phi_{q 1}=\phi_{q 2}=\phi_{q 3}=\phi_{q 4}=\phi^{y 1} \\
H_{0}^{s, y} & : \phi_{s 1}=\phi_{s 2}=\phi^{y 1}
\end{aligned}
$$

The alphabet m, q, s, y represent monthly, quarterly, semi-yearly and yearly dummies respectively. According to the first null hypothesis, $H_{0}^{m, q}$, the coefficients on monthly prices within quarters are identical. That is, if monthly data are grouped into quarters, the temporal aggregation condition requires the coefficients for January, February, and March within the first-quarter to be equal to justify the pooling of data together to construct the first quarter index [4]. According to the second null hypothesis the coefficient on monthly prices within half years are identical and the rest of the equations are obvious. Therefore, these six null hypotheses are used to test if house price indices generated at different levels of temporal aggregation are equal. If house prices are constant over the entire period of aggregation being considered, then any temporal aggregation structure leads to the same result and so the estimation of one price level for particular temporal aggregation is justified.

\subsection{Seasonality Analysis}

Seasonal analysis can be carried out by estimating a regression model where the dependent variable is hedonic property index $\left(\mathrm{PI}_{\mathrm{it}}\right)$ and a quadratic time trend is included as independent variable besides monthly dummies and seasonal dummies respectively [30]. The hedonic price index function for seasonal analysis is written as below:

$\mathrm{PI}_{\text {it }}=\beta_{0}+\beta_{1}$ Trend $_{i t}+\beta_{2}$ Trend $^{2}{ }_{\text {it }}+\beta_{3}$ Spring $_{\text {it }}+\beta_{4}$ Summer $_{i t}+\beta_{5}$ Fall $_{\text {it }}+\beta_{6}$ Jan $_{i t}+\beta_{7}$ Feb $_{i t}+\beta_{8}$ Mar $_{\text {it }}+\beta_{9}$ Apr $_{\text {it }}+\beta_{10}$ May $_{i t}+$ $\beta_{11} \operatorname{Jun}_{\text {it }}+\beta_{12} \operatorname{Jul}_{\text {it }}+\beta_{13}$ Aug $_{\text {it }}+\beta_{14}$ Sep $_{i t}+\beta_{15}$ Oct $_{i t}+\beta_{16}$ Nov $_{i t}+\beta_{17}$ Dec $_{i t}+\varepsilon_{i t}$

There are no four seasons in Malaysia. Therefore, these dummies are removed from the equation above and forming model 2.10.

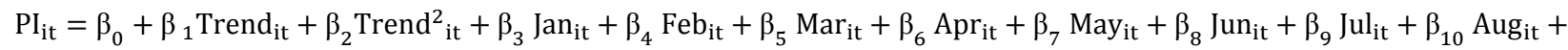
$\beta_{11}$ Sep $_{i t}+\beta_{12}$ Oct $_{i t}+\beta_{13}$ Nov $_{i t}+\beta_{14}$ Dec $_{\text {it }}+\varepsilon_{i t} \quad(2.10)$. 


\subsection{Seasonality Adjustment}

Seasonal adjustment used to adjust housing index that embedded with seasonal effect. The seasonal adjustment on quarterly sales data can be conducted by using seasonal index [12]. Moreover, the seasonal index can be developed by using simple ratio to moving average (centered) decomposition method [19,7]. Both formulas are stated as below in order to construct a seasonal adjusted housing index.

\section{a) CENTERED MOVING AVERAGE}

The moving average method is widely used to smooth a time series and to determine the seasonal component [16]. This approach will express thoroughly the trend and cyclical components of the series and the seasonal structure to be assumed constant from year to year. In other word, the boom or bust is occurring in the same intra-year periods. The centred moving average for 12 months will be carried out due to housing index in monthly basis in this study. The formula is stated as followed:

$$
\mathrm{MA}_{\mathrm{t}}=\left(\frac{\mathrm{A}_{\mathrm{t}+6}+2 \sum_{\mathrm{k}=1}^{11}\left(\mathrm{~A}_{\mathrm{t}+6-\mathrm{k}}\right)+\mathrm{A}_{\mathrm{t}-6}}{24}\right)
$$

Where:

$\mathrm{MA}_{t}=$ the centred moving average of arrivals for month $t$;

$\mathrm{A}_{t}=$ data point in month $t$;

$K \quad=$ number of lag

\section{b) SEASONAL INDEX}

In order to develop seasonal index it is necessary to derived ratios of observation to moving average that represented by $\mathrm{P}_{t}[16]$. it can obtained by merely dividing the original value of each housing index by the corresponding moving average figure for each month that come with percentage form as below:

$$
\mathrm{p}_{\mathrm{t}}=\frac{\mathrm{A}_{\mathrm{t}}}{\mathrm{MA}_{\mathrm{t}}} \times 100
$$

The seasonal index is obtained by average $\mathrm{P}_{t}$ for each month. After that, the original data point will divide by seasonal index of respective month to obtain deseasonalized data. The formula for deseasonalizing data is illustrated as below:

$$
\mathrm{S}_{\mathrm{t}}=\frac{\mathrm{Y}}{\mathrm{S}_{\mathrm{j}}}
$$

$\mathrm{S}_{\mathrm{t}} \quad=$ Deseasonalized data

$\mathrm{Y}=$ Original data points

$\mathrm{S}_{\mathrm{j}} \quad=$ Seasonal index

\subsection{DATA COLLECTION}

The following section will discuss the process in obtaining house price index through index construction methods that stated above. After that, the house price indices will be used to perform temporal aggregation and seasonality analysis which is main objective in this study.

\subsection{Sample Of Data}

The sample data is collected from Plentong which is a town under district of Johor Bahru. Plentong is a town that comprised of several residential area such as Bandar Bistari Perdana, Bandar Baru Kota Putri, Bandar Baru Permas Jaya, Bandar Baru Seri Alam,Desa Harmoni and etc. Plentong is located at the west part of Johor Bahru city centre and surrounded by flagship A and D of Iskandar region which had shown in Figure 1. Flaghip A is located at Johor City Centre that act as southern gateway development which involved key economic such as financial and urban tourism. Flagship D is located at eastern gate development which is Pasir Gudang and it acts as a manufacturing hub in southern region of Malaysia. The advantage of using Plentong town as study area is because it provides sufficient housing transaction particularly in double storey terrace house in developing model. It is because the housing index has to be constructing in most disaggregated level which is monthly index in this case. Therefore, seasonality analysis can be executed through monthly index. The time frame is started from year 2006 until 2011. So, housing performance before and after Global Financial Crisis 2008 for specific area which is Plentong can be observed through housing index. 


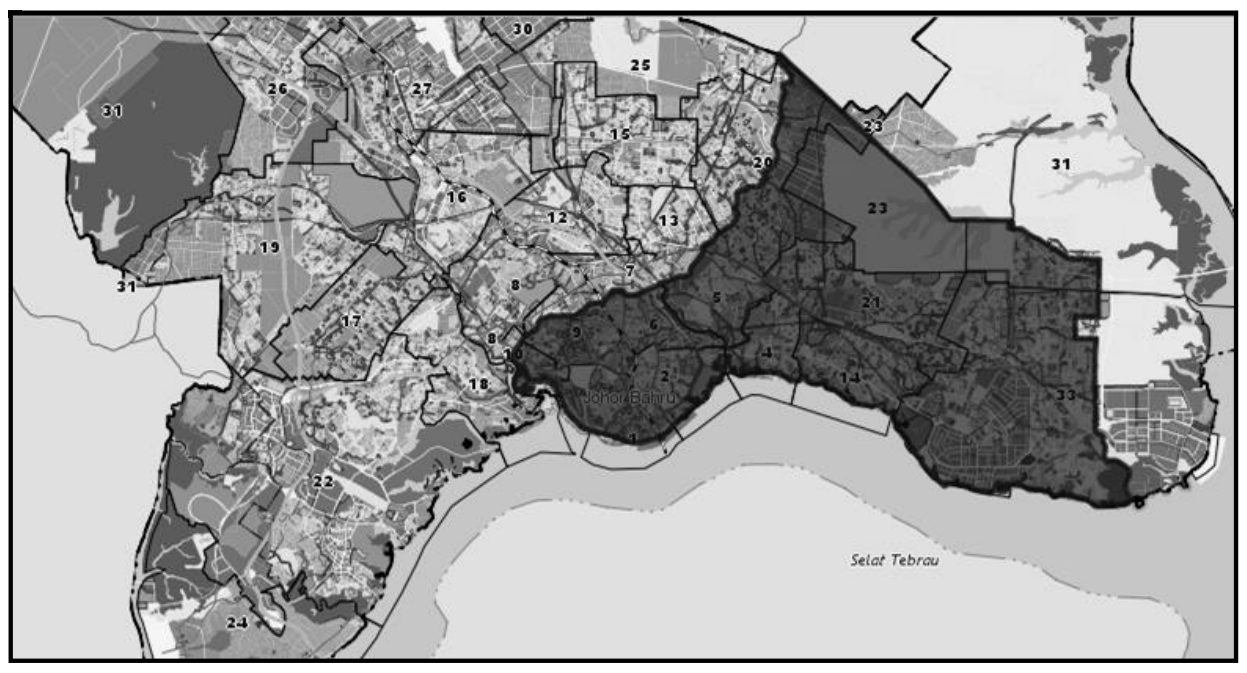

Figure 1 Location map of plentong

This study constructs a hedonic housing index using property transaction. In order to construct a reliable housing index this study will consider on two issues which are geographical boundary and types of property. The problem of geographical aggregation might cause sample selection bias due to different socioeconomic structure for each locality. Therefore, this study choose Plentong town where under the district of Johor Bahru, Malaysia. In addition, this housing index is particularly developed for double-storey terrace house. The selection of one type of residential property could minimize the heterogeneity between different types of property that may affect the reliability of the model. The housing index is developed in monthly, quarterly, semi-yearly and yearly from year 2006 to 2011. The housing index is constructed using hedonic time dummy method, Laspeyres index, Passche Index and Fisher Ideal Index in order to conduct temporal aggregation and seasonality analysis.

\subsection{VariableS}

This section will determine types of variables to be included in the hedonic model. According to previous research [1] land area of house contribute positively by $35 \%$ toward house price. The reason is bigger land size will provide variety of usage for homeowners such as larger car porch. In addition, larger built-up area also provides addition space to accommodate more people in a house. Thus it has positive effect on house price [3,25]. In Malaysia, the ownership of land is divided into leasehold and freehold. Leasehold property will be reverting back to state government in a period of time while freehold property will enjoy a perpetuity interest. Therefore, the advantage of freehold property will lead to higher price theoretically. Furthermore, Malaysia consists of two types of lot which are Bumiputra lot and International lot. Generally, Bumiputra lot will be offer in a cheaper price compare to International lot and the transaction is restricted within aborigines only. Therefore International lot has a wider market which allows foreign investor to buy and it may lead to higher price in international lot compare to Bumiputra lot. Types of property such as low and medium cost properties also contribute to house price. According to Seventh Malaysia Plan (1996-2000) and Eight Malaysia Plan (2001-2005) will provide affordable house for low income group in Malaysia [20]. Furthermore, private sectors are compulsory to construct $30 \%$ low cost housing in every residential development which monitored by local authority. These two types of properties are cheaper than ordinary properties. It may probably due to different design and materials. Hence, the variables discussed above are important in predicting house price and used to construct house price index.

\subsection{Descriptive Analysis}

The table below shows the descriptive statistics of the sample data used in constructing housing index. In general, there are 4,621 observations used to construct this housing index. Average house price in pool of data is RM 144,675.51. The minimum and maximum house prices are RM 13,000 and RM 680,000 respectively. The difference is RM 667,000.In addition, the average land size is bigger than the built up area of an average property which is 129.56 square metres compared to 105.95 square metres. The maximum land size of a property is 602.97 square metres while the minimum 58.52 square metres of land size. Overall, majority of the double storey terrace houses is medium cost double terrace house. The mean value of ethic 0.40 had shown that most of the transaction is International lot. The figures 0.87 identified most of double storey terrace house of Plentong town are freehold lot. 
Table 1 Descriptive statistic

\begin{tabular}{lllll}
\hline & \multicolumn{1}{c}{ Mean } & Std.dev & Min & Max \\
\hline House Price & $144,675.51$ & 1295.05 & 13,000 & 680,000 \\
House Price (In) & 11.69 & 0.01 & 9.47 & 13.43 \\
Land & 129.56 & 0.95 & 58.52 & 602.97 \\
Built & 105.95 & 0.60 & 46.22 & 304.62 \\
Types & 2.31 & 0.01 & 1 & 3 \\
Lot & 0.40 & 0.01 & 0 & 1 \\
Tenure & 0.87 & 0.01 & 0 & 1 \\
Total observation & 4,621 & & & \\
\hline
\end{tabular}

(Notes:Land= Land Area; Built= Built-up Area; Types 1= low cost double terraced house, $2=$ medium cost double terrace house, $3=$ double terrace house; Lot $1=$ bumiputra lot, $0=$ International lot; Tenure $1=$ freehold, $0=$ leasehold)

\subsection{DATA ANALYSIS}

This section consists of the process and analysis methods to investigate temporal aggregation and seasonality problems in housing index. In addition, the follow section will ascertain the reliability of hedonic mode in constructing house price index. After that, it will identify the temporal aggregation problem through risk and return of house price index which generated by different time frame. At last, it determines seasonal effect by using regression analysis.

\subsection{Reliability Of Hedonic Models}

Three types of hedonic models used to construct housing index time dummy, Laspeyres and Passche index. Hedonic time dummy method will run an overall regression in order to obtain an index. In this study, only the respective period ( $\mathrm{t}$ ) and the based period ( $\left.\mathrm{t}_{0}\right)$ will be pooled together in a regression model. This is to avoid abundance of time dummy variable when extending the period of time. Unlike hedonic imputation method it run separate regression or cross section regression for each respective $(\mathrm{t})$ and based period $\left(\mathrm{t}_{0}\right)$. The observation in running cross section regression is about 50 on average in this study, which is higher than 32 observations as recommended by [27] to establish a viable model. The table below shows one of regression models from longitudinal and cross section regression to show the reliability of model. In overall, the models used in constructing housing index able to achieved adjusted R square in 0.75 and above which considered as good models.

Table 2 Comparison of models

\begin{tabular}{ccc}
\hline & Hedonic Longitudinal Regression & Hedonic Cross-section Regression \\
\hline & Time dummy & Laspeyres \& Paasche \\
Land & Coefficient/t value & Coefficient/t value \\
Built & $0.0019 / 4.207^{* * *}$ & $0.0019 / 5.425^{* * *}$ \\
Types & $0.0074 / 5.818^{* * *}$ & $0.0054 / 4.509^{* * *}$ \\
Lot & $0.2038 / 3.450^{* * *}$ & $0.2994 / 5.460^{* * *}$ \\
Tenure & $-0.1213 /-2.006^{* *}$ & $-0.2265-3.130^{* * *}$ \\
Adjusted R Square & $0.1970 / 1.935^{*}$ & $0.1197 / 1.237$ \\
\hline
\end{tabular}

(Notes:Dependent variable $=$ House price in log form and Independent variable are Land $=$ Land Area, Built $=$ Built-up Area, Types $1=$ low cost double terraced house, $2=$ medium cost double terrace house, $3=$ double terrace house; Lot $1=$ bumiputra lot, $0=$ International lot; Tenure $1=$ freehold, $0=$ leasehold, )

*** Significant at 0.01Level

** Significant at 0.05 Level

* Significant at 0.1Level 
Table 2 indicated that most of the variables above shown significant effect toward house price. Particularly, land area, types of property, and built-up area of a property are highly significant in both types of regression model. Lot and tenure of property are significant at $5 \%$ and $10 \%$ level respectively in a model. The negative coefficient for variable lot indicates that international lot will lead to higher sale price of house. Furthermore, their t-value sign is also acceptable in explaining their effect on house price. Land area and built up area are contributed positive effect on house price because people are willing to pay more for larger land size and built up area. Ordinary type of double terrace is higher value compare to low cost and medium cost of double storey terrace house. In addition, freehold property tends to be more valuable compare to leasehold property as shown in the table. Therefore, the housing indices created by these models are reliable. Thus, these models used to construct housing index as below.

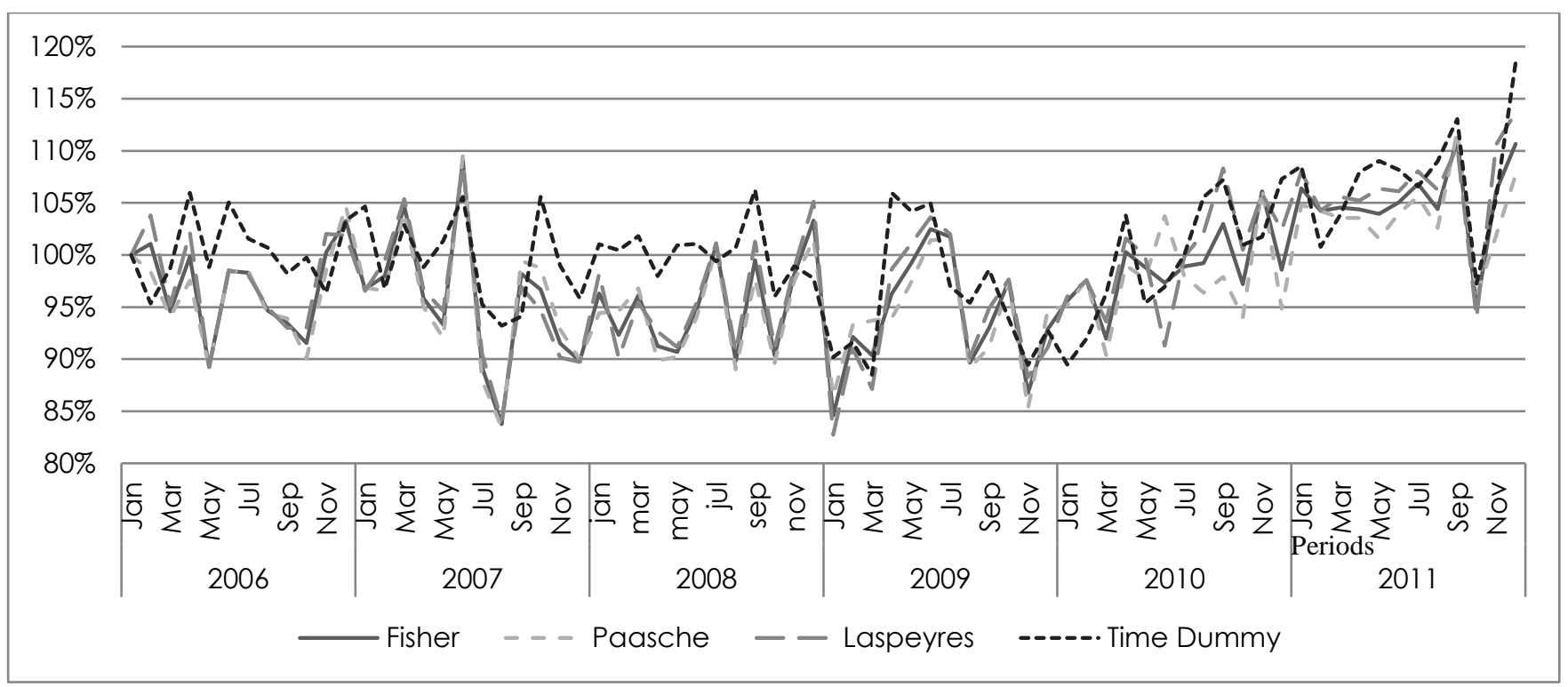

Figure 2 Performance of double-storey terrace house from Year 2006-2011

The line chart above depicts performance of double storey terrace house in Plentong town from year 2006 until 2011 . The fluctuation of housing performance from year 2006 until 2011 is stable. Furthermore, from year 2006 until 2009 the housing performance is at the downtrend. This scenario may be affected by Global Financial Crisis year 2008. After that, it starts to rebound at year 2010. This trend is ascertained by using various types of index construction method which are hedonic time dummy, Laspeyres index, Passche index and Fisher Index. These indices had shown the similar trend to reflect the housing performance of Plentong town.

\subsection{Effects Of Temporal Aggregation}

Generally, this section will discuss temporal aggregation of house price index in Plentong. Temporal aggregation problem can only be tested with the time dummy model as the coefficient of time dummy is needed to ascertain the problem. As mentioned in previous section, there are six null hypothesis used i.e. whether monthly coefficients is equal to quarterly, half-year and yearly coefficient, quarterly coefficient equal to half year and yearly coefficient and half year coefficient equal to yearly coefficient. The findings for these hypotheses are indicated by table 3 .

Table 3 ANOVA of coefficient

\begin{tabular}{cccc}
\hline & Month & Quarter & Half year \\
\hline Quarter & $25.02(0.000)$ & & \\
Half year & $5.47(0.020)$ & $11.55(0.000)$ & \\
Year & $6.85(0.009)$ & $11.59(0.000)$ & $0.04(0.827)$ \\
\hline
\end{tabular}

(Notes: F value used to identify the aggregation problem and ( ) represented p-value,) 
The month and quarter coefficient is significantly different where the F-value is 25.02. The difference between half-year and yearly coefficients could not be identified due to insignificant F-value. Therefore, the result above show that house price index should be represented in the most disaggregated level. This findings is consistent with findings from previous studies $[4,6,17]$.

Table 4 Mean return of house price index

\begin{tabular}{ccccc}
\hline & Time Dummy & Laspeyres & Passche & Fisher \\
\hline Month & 100.50 & 98.27 & 96.99 & 97.62 \\
Quarter & 104.95 & 102.07 & 100.24 & 101.14 \\
Half- year & 102.35 & 102.50 & 102.59 & 102.55 \\
Year & 102.46 & 102.50 & 102.50 & 102.50
\end{tabular}

The table above indicated the mean return for the four types of indices. Obviously, all indices seem to agree that higher aggregated house price index produced higher mean return compared to lower aggregate house price index. For example, the difference is about $4 \%$ in average house price index between monthly and quarterly mean return for time dummy method. This scenario is also repeated in other types of index construction method.

Table 5 Annualised change (\%) of mean return

\begin{tabular}{|c|c|c|c|c|}
\hline & Time Dummy & Laspeyres & Passche & Fisher \\
\hline Month & $5.70 \%$ & $6.46 \%$ & $5.13 \%$ & $5.42 \%$ \\
\hline Quarter & $2.86 \%$ & $2.54 \%$ & $1.39 \%$ & $1.90 \%$ \\
\hline Half-year & $2.01 \%$ & $2.05 \%$ & $1.92 \%$ & $1.98 \%$ \\
\hline Year & $1.96 \%$ & $2.11 \%$ & $1.99 \%$ & $2.05 \%$ \\
\hline
\end{tabular}

Table 5 depicts an annualised change (\%) mean return for different periods. Following previous research [21], annualised returns measure the returns of investment in owner occupied housing for a one-year holding period. Monthly mean return leads as compared to other periods recorded in the table above. Furthermore, aggregation period for quarter and half year also yield different mean return for different types of index construction method. For example, quarter mean return for time dummy is $2.86 \%$ but for Passche is $1.39 \%$. The yearly mean return for all types of indices is consistent. All index construction methods share a similarity where mean returns is different for each aggregated periods.

Table 6 Annualised change (\%) of volatility

\begin{tabular}{|c|c|c|c|c|}
\hline & Time Dummy & Laspeyres & Passche & Fisher \\
\hline Month & $7.81 \%$ & $11.35 \%$ & $9.81 \%$ & $10.70 \%$ \\
\hline Quarter & $4.50 \%$ & $7.33 \%$ & $4.33 \%$ & $5.80 \%$ \\
\hline Half year & $4.30 \%$ & $5.56 \%$ & $4.72 \%$ & $5.08 \%$ \\
\hline Year & $2.86 \%$ & $2.83 \%$ & $2.49 \%$ & $2.35 \%$ \\
\hline
\end{tabular}


The volatility of house price index in Plentong is indicated in table 6. If the house price index is aggregated into yearly basis, it will induce lower volatility compared to other periods with lower levels of aggregation. Monthly price index developed by Laspeyres method had produced highest volatility among all types of index construction methods at $11.35 \%$. All methods show reduction of volatility from month towards year index. Our study rejects the findings carried out by [6,21] which differences of returns and volatilities are small among different level of temporal aggregation. In contrast, this result agreed with [4] who found that temporal aggregation smooths price variability across time. To conclude, temporal aggregation will mislead the risk and return of housing market.

\subsection{Seasonality Analysis}

This section will ascertain the existence of seasonal effects in house price index for Plentong. Any seasonality effects in house price index should be controlled in order to determine the real performance of housing market. The seasonal variation is tested by regressing the house price index against a quadratic trend and dummies for month through the t-value of the models. All four types of index will be used for the analysis. According to table 7, the price trend generated from all four indices show similar results. where the price trend for double storey terrace house is decreasing in a decreasing rate. This scenario is statistically significant. It can also be observed from the line chart in previous section.

Table 7 Seasonality of house price index in Plentong

\begin{tabular}{|c|c|c|c|c|}
\hline & Time Dummy & Laspeyres & Passche & Fisher \\
\hline Adjusted R Square & t-value & t-value & t-value & t-value \\
\hline $\mathrm{t}$ & $-4.008 * * *$ & $-3.854 * * *$ & $-3.358 * * *$ & $-3.854 * * *$ \\
\hline$t^{2}$ & $4.865 * * *$ & $5.112 * * *$ & $4.457 * * *$ & $5.109 * * *$ \\
\hline Mar & -1.142 & -0.749 & -0.285 & -0.563 \\
\hline Apr & 0.591 & 0.025 & -0.538 & -0.250 \\
\hline May & -0.086 & -0.803 & -1.234 & -1.064 \\
\hline Jun & 0.629 & 0.326 & 1.405 & 0.880 \\
\hline Sep & 0.264 & 0.245 & 0.089 & 0.181 \\
\hline Oct & -1.259 & -1.685 & -1.607 & $-1.750^{*}$ \\
\hline Nov & -1.457 & -0.383 & -0.622 & -0.525 \\
\hline Dec & - & - & - & - \\
\hline
\end{tabular}

According to the results above, seasonal effects do exist in house price index of Plentong. Laspeyres, Passche and Fisher indices indicated August effects in price index while time dummy index indicates February effects. It means that the house price in Plentong town hits the lowest value in August, February and October. It may due to less buyers in these months. In addition, this findings strongly agrees with previous research from $[10,13,18,24,26]$ that seasonal problems exist in Malaysia housing price index. The house price index should be seasonally adjusted or using moving average before release to public.

\subsection{Seasonal Adjustment}

In previous section, seasonality analysis ascertains the seasonal effect in August, February and October. Thus, it accompany by seasonal adjustment on Passche, Laspeyres, Fisher and Time dummy housing index in this study. Furthermore, this section will also explore the differences between seasonal adjusted housing index and non seasonal adjusted housing index. It will be evaluated based on $\mathrm{F}$ test and mean and volatility of housing price index. The seasonal adjusted housing index is provided in appendices of this paper. The motive of this section is to identify the importance of seasonal adjusted and non seasonal adjusted housing index. 
a) MEAN AND VOLATILITY BETWEEN SEASONAL ADJUSTED AND NON SEASONAL ADJUSTED HOUSING INDEX

Table 8 Comparison of mean and volatility

\begin{tabular}{ccc}
\hline & Mean & Volatility \\
\hline FHPI & $97.618 \%$ & $6.019 \%$ \\
AFHPI & $97.621 \%$ & $5.705 \%$ \\
\hline DFF & $0.002 \%$ & $-0.314 \%$ \\
\hline PHPI & $96.994 \%$ & $5.795 \%$ \\
APHPI & $96.998 \%$ & $5.359 \%$ \\
\hline DFF & $0.005 \%$ & $-0.436 \%$ \\
\hline LHPI & $98.277 \%$ & $6.695 \%$ \\
ALHPI & $98.279 \%$ & $6.462 \%$ \\
\hline DFF & $0.002 \%$ & $-0.233 \%$ \\
\hline DTHPI & $100.499 \%$ & $5.718 \%$ \\
\hline ADTHPI & $100.497 \%$ & $5.347 \%$ \\
\hline DFF & $-0.002 \%$ & $-0.371 \%$ \\
\hline
\end{tabular}

FHPI = Fisher Ideal Housing Price Index

AFHPI = Seasonal Adjusted Housing Price Index

PHPI = Passche Housing Fisher Ideal Price Index

APHPI = Seasonal Adjusted Passche Housing Price Index

LHPI = Laspeyres Housing Price Index

ALPHI $\quad=$ Seasonal Adjusted Laspeyres Housing Price Index

DTHPI = Time Dummy Housing Price Index

ADTHPI = Seasonal Adjusted Time Dummy Housing Price Index

$\mathrm{DFF}=$ Differences between seasonal adjusted housing index and non seasonal adjusted housing index

Table 8 indicated the differences of mean and volatility between non seasonal adjusted housing index and seasonal adjusted housing index that developed from four methods. Obviously, there are no significant changes for both mean and volatility of housing price index that shown by four types of housing index above. For an example, the volatility of seasonal adjusted Passche housing price index recorded a drop of $0.322 \%$ compare to non seasonal adjusted Passche housing price index and it is a biggest change in volatility among four types of housing index. Besides that, the biggest difference between mean of non seasonal adjusted and seasonal adjusted housing price index is only $-0.005 \%$ that constructed by Passche approach. The difference of mean and volatility from non adjusted housing price index and adjusted housing price index is ranging from $-0.002 \%$ to $0.005 \%$ and $-0.436 \%$ to $0.233 \%$ respectively.

b) ANOVA OF SEASONAL ADJUSTED AND NON SEASONAL ADJUSTED HOUSING INDEX

Table 9 ANOVA

\begin{tabular}{lcc}
\hline & F-value & p-value \\
\hline FHPI /AFHPI & $5.38 \mathrm{E}-06$ & 0.998153 \\
PHPI /APHPI & $2.34 \mathrm{E}-05$ & 0.996145 \\
LHPI / ALHPI & $3.95 \mathrm{E}-06$ & 0.998418 \\
DTHPI /ADTHPI & $4 \mathrm{E}-06$ & 0.998408 \\
\hline
\end{tabular}

Table above indicated ANOVA of seasonal adjusted and non seasonal adjusted housing index. The result above had been statistically proved that insignificant difference between seasonal adjusted housing index and non seasonal adjusted housing index that constructed from four methods. There is no p-value with 0.00 in comparison above which can determine the significant difference between seasonal adjusted housing index and non seasonal adjusted housing index. Although the difference between seasonal adjusted housing index and non seasonal adjusted housing index is insignificant but housing index is encouraged to be seasonal adjusted in order to reflect real performance of housing market especially housing derivatives market that required high precision of housing index. 


\subsection{CONCLUSION}

This study attempts to ascertain whether temporal aggregation and seasonality effect exists in Malaysian house price index using the study area of Plentong Johor Bahru. The first results found that mean return and volatility is different for month, quarter, half year and year. This may mislead investors in terms of risk and return in housing performance. Furthermore, five out of six null hypotheses for temporal aggregation analysis had been rejected. This result suggests that house price index should be represented in lowest level of aggregation. Secondly, seasonality analysis from this study confirmed that august effect exists in house price index of Plentong, meaning that house prices of double storey terrace houses in Plentong is low during august. Thus, seasonal adjustment used to develop a seasonal adjusted housing index. ANOVA had shown that differences in both seasonal adjusted housing index and non seasonal adjusted housing index is insignificant. Although it is insignificant but seasonal adjustment can developed more realistic housing index that can reflect housing performance which is needed in financial product that based on housing index such as housing derivative. Hence, price index in Malaysia should be seasonally adjusted and represented using the monthly (lowest level) of temporal aggregation. However, the hedonic models used in this study do not include spatial elements such as coordinates and future study is recommended to adopt spatial hedonic model for determining temporal aggregation and seasonality problems in house price index.

\section{References}

Abdul Hamid Mar Iman. (2007). Combining Geographic Information System and Regression Model to Generate Locational Value Residual Surfaces in the Assessment of Residential Property Values. Pacific Rim Property Research Journal, 13(1), 35-62.

Brewer, K.R.W. (1973). Some Consequences Of Temporal Aggregationand Systematic Sampling For ARIMA And ARMAX Models. J. Econometrics 1, $133-154$.

Carroll, T. M., Clauretie, T. M., and Jensen, J. (1996). Living Next to Godliness: Residential Property Values and Churches. Journal of Real Estate Finance and Economics, 12(3), 319-330.

Calhoun, C. A., Chinloy, P., \& Megbolugbe, I. F. (1995). Temporal Aggregation And House Price Index Construction. Journal of Housing Research, 6, 419-438. Developments in the Housing Market and Implications on Financial Stability 2012. Bank Negara Malaysia.

Englund, P., Quigley, J. M., \& Redfearn, C. L. (1999). The Choice Of Methodology For Computing Housing Price Indexes: Comparisons Of Temporal Aggregation And Sample Definition. The Journal Of Real Estate Finance And Economics, 19(2), 91-112.

Gardner Jr, E. S., \& McKenzie, E. D. (1985). Forecasting Trends In Time Series. Management Science, 31(10), $1237-1246$.

Geltner, D. (1993). Temporal Aggregation In Real Estate Return Indices. Real Estate Economics, 21(2), 141-166.

Greene, W.H. (2008), Econometric Analysis. Pearson Prentice Hall. Upper Saddle River. NJ

Harris, J. C. (1989). The Effect Of Real Rates Of Interest On Housing Prices. The Journal Of Real Estate Finance And Economics, 2(1), 47-60.

Haan J.D and Diewert.E (2013).Handbook on Residential Property Price Indices (RPPIs).European Union. Belgium.

Ittig, P. T. (1997). A Seasonal Index For Business. Decision Sciences, 28(2), 335-355.

Kaplanski, G., \& Levy, H. (2012). Real Estate Prices: An International Study Of Seasonality's Sentiment Effect. Journal of Empirical Finance, $19(1), 123-146$.

Kaplan Schweser (2011), CFA Level 2 Book 1: Ethical And Professional Standards, Quantitative Methods, And Economics, United States of America.

Karaganis, A. N. (2011). Seasonal And Spatial Hedonic Price Indices. Journal of Property Investment \& Finance, 29(3), 297-311.

Lim, C., \& McAleer, M. (2001). Monthly Seasonal Variations: Asian Tourism to Australia. Annals of Tourism Research, 28(1), 68-82.

Malaysia, G. D. P., \& Trend, C. H. G. (2011). BNM Annual Report 2012.

Miller, N., Sah, V., Sklarz, M., \& Pampulov, S. (2012). Correcting for the Effects of Seasonality on Home Prices. Appraisal Journal, 80(1).

Makridakis, S., Andersen, A., Carbone, R., Fildes, R., Hibon, M., Lewandowski, R., . \& Winkler, R. (1982). The Accuracy Of Extrapolation (Time Series) Methods:Results Of A Forecasting Competition. Journal Of Forecasting, 1(2), 111-153.

Ministry of Housing and Local Government Malaysia (2000). Buletin Perangkaan Perumahan 2000, Percetakan Nasional Berhad, Kuala Lumpur.

Owusu-Ansah, A. (2013). Construction Of Property Price Indices: Temporal Aggregation And Accuracy Of Various Index Methods. Property Management,31(2), 115131.

Pakes, A. (2002). A Reconsideration of Hedonic Price Indices with an Application to PC's (No. w8715). National Bureau of Economic Research.

Rayburn, W., Devaney, M., \& Evans, R. (1987). A Test of Weak-Form Efficiency in Residential Real Estate Returns. Real Estate Economics, 15(3), $220-233$.

Reichert, A. K. (1990). The Impact Of Interest Rates, Income, And Employment Upon Regional Housing Prices. The Journal of Real Estate Finance and Economics, 3(4), 373-391.

Rodriguez, M. and Sirmans, C. F. (1994). Quantifying the Value of a View in Single-Family Housing Markets. Appraisal Journal, 62(4), 600-603.

Rosen, H. S. (1979). Housing Decisions And The US Income Tax: An Econometric Analysis. Journal of Public Economics, 11(1), 1-23.

Schwann, G. M. (1998). A Real Estate Price Index For Thin Markets. The Journal of Real Estate Finance and Economics, $16(3), 269-287$.

Wei, W.W.S. (1979). Some Consequences Of Temporal Aggregation In Seasonal Time Series Models. In Seasonal Analysis of Economic Time Series, Ed. A. Zellner, 433-444. Washington, D.C.; U.S. Department of Commerce, Bureau of the Census

Wooldridge, J.M. (2006). Introductory Econometrics. A Modern Approach. Thomson.South-Western. Mason. OH.

Wilhelmsson, M. (2009). Construction and Updating Of Property Price Index Series: The Case Of Segmented Markets in Stockholm. Property Management,27(2), 119137. 